\title{
STUDY HABIT OF POST-GRADUATE TRAINEES AND RESIDENTS IN MEDICINE AND MAJOR BARRIERS IN ACHIEVING AN EFFECTIVE TRAINING: A MULTI- INSTITUTIONAL SURVEY (PRELIMINARY REPORT)
}

\author{
MUHAMMAD ABDUR RAHIM ${ }^{1}$, SHAHANA ZAMAN ${ }^{2}$, MD. ROBED AMIN ${ }^{3}$, ABED HUSSAIN KHAN ${ }^{4}$, MOHAMMAD \\ SHAHJAHAN KABIR ${ }^{5}$, AKM SHAHEEN AHMED ${ }^{1}$, TABASSUM SAMAD ${ }^{6}$, MEHRUBA ALAM ANANNA ${ }^{6}$, JAMAL \\ UDDIN AHMED ${ }^{1}$, HASNA FAHMIMA HAQUE ${ }^{1}$, PRATIK DEWAN ${ }^{1}$, MD. DELWAR HOSSAIN ${ }^{1}$, MD. RAZIUR \\ RAHMAN $^{5}$, AKM MUSA ${ }^{1}$, KHWAJA NAZIM UDDIN ${ }^{1}$
}

\begin{abstract}
Background and objectives: Large number of unsuccessful candidates in post-graduate (PG) medical examinations prompted us to evaluate how candidates prepare themselves during training years, their educational resources and the obstacles against a good training.

Methods: This multi-center survey was done in 4 PG medical teaching institutes in Dhaka from January to March, 2012. A total of 67 PG medical students responded to a preformed questionnaire by personal contact or electronically.

Results: Out of 67 students, 31 were male and 36 were female (M: F ratio was 1:1.2). Mean age was 31.3 (range 27 - 39) years. Most (59, 88\%) of them were married and 45 (76\%) were parents. All the respondents had entered into a post graduate course (FCPS/ MD/ Diploma). Their monthly remuneration was d"20000.00 taka. Their training was recognized as full time and residential. They were scheduled to stay at wards for 6-8 hours a day and their responsibilities included regular patients' care, attending ward rounds and bed side teaching. They had to attend lectures 2-4 hours/ week. The mean study time of the students were 14 (range 7 - 60) hours / week. About 60\% of this time they passed in libraries obtaining theoritical knowledge and preparing for written examinations using texts and notes. Only 5 (7.4\%) students used electronic sources for solving practical problems in patient management. On an average, they passed 20 hours/ week in clinical and bed side learning, mostly in later ( $4^{\text {th }}$ and $5^{\text {th }}$ ) years of training. Not a single student was satisfied with his/ her part in training. Over 50\% of them were not satisfied with the contribution from the unit/ institution as well. Students found MOCK examinations and orientation programs very fruitful. Lack of a structured training program, familial responsibility and inadequate remunerations were the main barriers in the training years.

Conclusion: Most of the PG students passed a significant amount of time for their study in libraries rather than bed side and the main goals were preparation for written examinations rather than clinical problem solving. Inappropriate training program, familial liabilities and inadequate remunerations were the main barriers.
\end{abstract}

Key words: Study habit, post-graduate, residents, medical students

\section{Introduction}

The highest level of competency is expected from the students in final assessment of post-graduate (PG) medical examinations. Students' competency is generally assessed in 3 major areas; theory, clinical and practical. Students acquire knowledge, experience and efficiency during the training years through continuous process of study, taking patients' care, bed side teaching from clinical teaching stuffs, attending lectures, continuing medical education programs (CME), journal clubs, seminars and by finding newer evidences through electronic sources etc. In spite of highest level of efforts by students and trainers, success rate in PG examinations is disappointing. In Fellowship examination (FCPS) of Bangladesh College of Physicians and Surgeons

1. Department of Medicine, BIRDEM

2. Department of Cardiology, NICVD

3. Department of Medicine, $\mathrm{DMCH}$

4. Department of Medicine, BSMMU

5. Department of Emergency, BIRDEM

6. Department of Nephrology, BIRDEM

Bangladesh J Medicine 2013; 24 : 10-13 
(BCPS) it is $2.5-16.8 \%$, in Doctor of Medicine (MD) it is $30-50 \%$, Diploma $30-60 \%$ and in Membership examination (MRCP) of Royal Colleges of Physicians it is $44.2 \% .^{1-3}$

Success in PG examinations depend on effective utilization of training years, well orientation regarding the assessment process and the finest level of performance on examination day(s). Unfortunately, many students are not serious at early years of training and obtaining training certificate is their main goal. So, they become overburdened with studies later on. Many of them become unsuccessful and have to appear repeatedly in examinations. Thus, there occurs wastage of productive years at the beginning of their career. Nearly $60 \%$ of PG students become depressed ${ }^{4}$ and their performance further deteriorates. So, this study was designed to see how PG medical students utilize training years and what the major difficulties are during this period.

\section{Methods:}

This survey was done in 4 PG medical institutes in Dhaka, Bangladesh over first 3 months of 2012. One hundred PG medical students, who were undertaking training for medicine and/ or any other allied subspeciality were given a 50-item pre-formed questionare by personal contact or by e-mail. Satisfaction level in training was measured in a visual analogue scale of $0-25(<13=$ not satisfactory, 13 $<15$ = satisfactory, $15-<18=$ good, e" $18=$ highly beneficial). Sixty seven students filled up the form and returned it back. PG medical students, who had completed their training and appeared in examinations, either passed or failed and those trainees who did not pass FCPS part-I, MRCP part-I and those who did not enter into MD or Diploma courses were excluded from the study. The aim of this study was to evaluate how much time PG medical students utilized for study, their purpose of study, study materials and place and barriers against a good training.

\section{Results}

Total number of students was 67 (response rate 67\%). Male were 31 and female 37 (M: F ratio 1: 1.2). Mean age was 31.3 years (range 27-39 years). Fifty nine $(88 \%)$ were married and $45(76 \%)$ were parents. Their average monthly remuneration was $<20,000.00$ taka.

They were from Bangladesh Institute of Research and Rehabilitation in Diabetes, Endocrine and Metabolic Disorders (BIRDEM) (33, 49.3\%), Bangabandhu Sheikh Mujib Medical University (BSMMU) (14, 20.9\%), Dhaka Medical College Hospital
(DMCH) $(15,22.4 \%)$ and National Institute of Cardiovascular Diseases (NICVD) (5, 7.4\%).

Most of the respondents were in their $3^{\text {rd }}$ and $4^{\text {th }}$ year of training (Figure-1). Their training was taken as fulltime and residential and their responsibilities were shown in table-I. Only $8(11.9 \%)$ students were involved in research activity and 5 (7.4\%) students had responsibility of teaching undergraduate students.

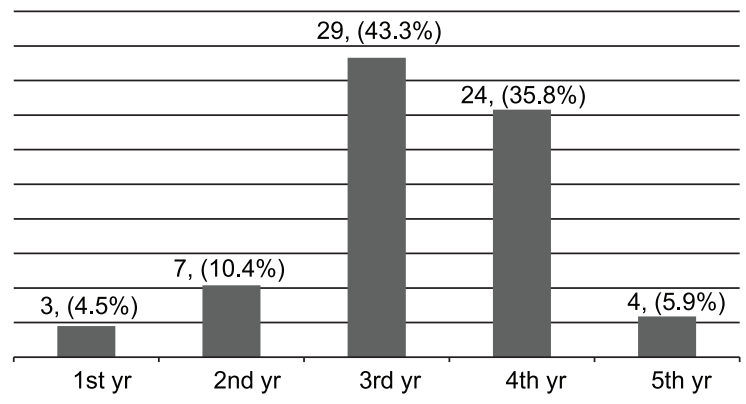

Fig.-1: Distribution of students according to year of training

Table I

Responsibilities of trainees

\begin{tabular}{lcc}
\hline Activity & Frequency/ comment & Percent \\
\hline Patient care & 67 & 100 \\
Ward round & 67 & 100 \\
Journal clubs & 67 & 100 \\
Grand rounds & 62 & 92.5 \\
Seminars & 67 & 100 \\
OPD placement & 16 & 23.9 \\
Teaching & 5 & 7.4 \\
Research & 8 & 11.9 \\
Presentations & 21 & 31.3 \\
Skilled activity & Occasional & \\
Lectures & 2- 4 hours / week & \\
Clinical classes & 6- 12 hours / week \\
\hline
\end{tabular}

Mean study time in this study was 14 hours per week. As the students approached towards examinations, their study time increased. A $1^{\text {st }}$ year trainee spent 8 hours per week, whereas a final year $\left(4^{\text {th }}\right.$ year for FCPS and $5^{\text {th }}$ year for MD) student spent about 60 hours per week (Figure-2). Sixty percent of this time they used for obtaining theoretical knowledge by reading texts and notes in libraries as preparation for written examinations. They passed 20 hours per week in wards for clinical skill gain particularly for long and short cases. Practical part of preparation was least emphasized (Figure-2). Students attending orientation program $(19,28.4 \%)$ and MOCK 
examinations $(23,34.3 \%)$ found these to be highly beneficial.

Table-II

Distribution of students according to speciality

\begin{tabular}{lcc}
\hline Speciality & Frequency & Percent \\
\hline Medicine & 57 & 85 \\
Cardiology & 13 & 19.4 \\
Endocrinology & 6 & 8.9 \\
Nephrology & 6 & 8.9 \\
Gastroenterology & 5 & 7.4 \\
Dermatology & 3 & 4.5 \\
Neurology & 2 & 3 \\
\hline
\end{tabular}

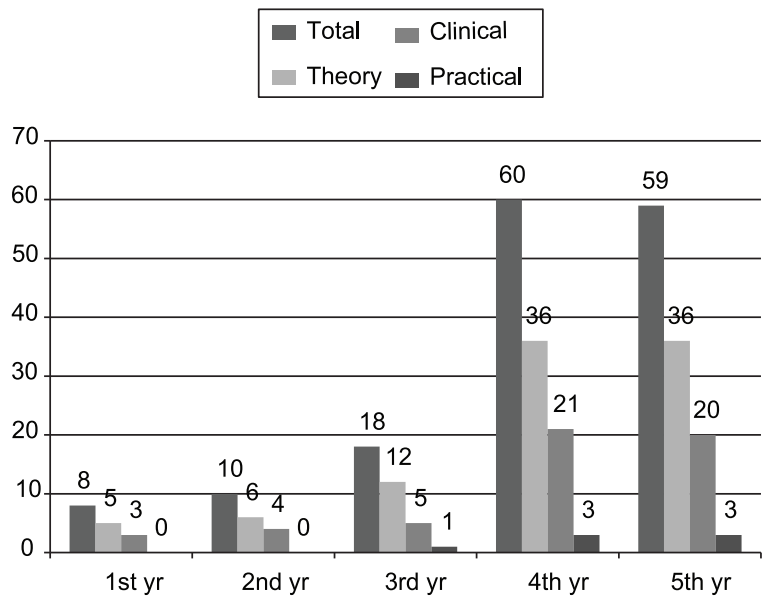

Fig.-2: Study hours of students according to training years

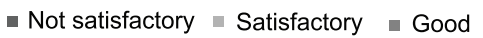

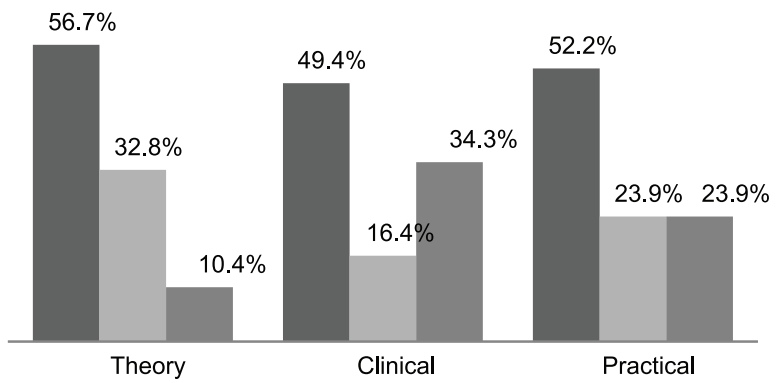

Fig.-3: Students' satisfaction regarding contribution of trainers

Most students read texts $(67,100 \%)$ and notes (54, $80.6 \%)$. Only $5(7.4 \%)$ students used electronic sources for seeking best evidences for treating their patients on a regular basis. Preparation for examination $(57,85.1 \%)$ and patient management $(34,50.7 \%)$ were the main purposes of study.

Not a single student was satisfied with his/ her part of training. About $50 \%$ of them were not satisfied with the trainers' contribution as well (Figure-3).

There were 3 major barriers; lack of a well-structured training program $(39,58.2 \%)$, inadequate financial remuneration $(67,100 \%)$ and familial and social responsibilities $(53,79.1 \%)$.

Forty four (65.7\%) students predicted that after completion of training, it will be satisfactory, 11 (16.4\%) students thought it to be good and 2 (3\%) students thought it will be highly beneficial. Ten $(14.9 \%)$ students did not give any comment in this regard.

\section{Discussion}

To the best of our knowledge, no studies have been published on the PG medical students' reading habit in our country. As large number of students fail in each attempt, we tried to evaluate how students prepare during the training years, their educational resources and difficulties.

Response rate in this survey was $67 \%$. In a similar survey published in 2010, response rate was $45.8 \% .^{5}$ In another study response rate was $71 \% .6$ In our study $55.2 \%$ respondents were female. Response rate was higher $(70 \%)$ among females in another study. ${ }^{6}$ Most (85\%) respondents in this series were preparing for medicine, $49.3 \%$ for other subspeciality, 34 students were preparing for more than one degrees. Internal medicine was preferred by $68 \%$ students and $17 \%$ preferred subspeciality in a similar study. ${ }^{6}$

Mean study time in this study was 14 hours per week. It was seen in our study that as students proceeded towards examinations, their mean study hour increased. In one study it was seen that mean study hours was 4.3 hours per week though the respondents passed 4.7 hours per week for studying nonmedical materials. ${ }^{6}$ In another small study, internal medicine residents on inpatient wards reported an average reading time of 8.7 hours per week. ${ }^{7}$ In a similar survey, it was seen that $77.7 \%$ students passed $<7$ hours per week for study and average study hour declined with advancing years. ${ }^{5}$ Similar observation of declining duration of study hours with advancing years appeared among undergraduate medicine clerks. ${ }^{8}$ One explanation for this opposite nature of study hours might be that, our students are not serious throughout the training period, rather they are more serious during the final years.

Students passed $60 \%$ of study time preparing for written examinations and 33\% for clinical cases in current study. In another study, students passed over two-thirds of the study time for ambulatory reading 
and the rest for inpatient topics. ${ }^{6}$ Practical part of study was grossly neglected in our study. Possibly for this reason, in spite of good performance in written examinations (pass rate $54-77 \%$ ), many students performed badly in objective structured practical examinations (OSPE) of BCPS. ${ }^{1,2}$

In the current study, preparation for examination was the main purpose followed by patient management. In other study, individual patient encounter was the main purpose $(81.4 \%) .{ }^{5}$ Students responded that medical problems of individual patients and preparation for presentations were main reasons for study in another report. ${ }^{6}$ For residents, reading solidifies knowledge acquired from patient care experiences. ${ }^{9-13}$ In our study, 5 students had the responsibility of teaching undergraduate students. It was seen that, residents on inpatient rotations required to teach and may spend more time reading than ambulatory residents who had few formal teaching responsibilities. ${ }^{6}$

Students mostly read texts and notes, $7.4 \%$ students used electronic sources regularly for patient care in current study. Electronic sources were the most commonly used materials in other studies and Uptodate $^{\circledR}$ medical software was the most commonly used individual online source. ${ }^{6,5,8}$ However, in one study, it was seen that residents relied on rounds and textbooks. ${ }^{14}$ The shift from textbooks, journal and pocket manuals to online sources started in the early 1990s. ${ }^{15,7,16,17}$

Absence of a well-structured training program, familial and social responsibility and inadequate financial remunerations were the main barriers in this study. Training program is being changed and updated continuously throughout the world. Personal and familial responsibilities, lack of motivation and lack of time were main barriers in a similar study. ${ }^{6}$

Our study had some limitations. Small number of students responded over short period of time. Respondents were from Dhaka city only, not peripheral teaching institutes. Sampling technique was not randomized. This study included students' opinion only, not trainers' view.

In summary, it can be said that students pass sufficient time for study at least in advanced years, but it is mostly library based. For a better outcome, students will have to bring the library into the clinical wards. It is recommended that training should be more structured, well organized, examination oriented and supervised. Number of students should be limited to a particular unit. Examination system might be reviewed. A part of students' training years performance should contribute at the final assessment. Students' financial remunerations should be increased so that they can concentrate to their main goal.

\section{References}

1. BCPS year book. $8^{\text {th }}$ ed. Dhaka. 2011:82.

2. $\quad$ BCPS year book. $9^{\text {th }}$ ed. Dhaka. 2012:77.

3. www.mrcpuk.org , $\mathrm{MRCP}(\mathrm{UK})$ Home , Results

4. Yousuf A, Ishaque S, Qidwai W. Depression and its associated risk factors in medical and surgical post graduate trainees at a teaching hospital: a cross sectional survey from a developing country. JPMA. 2011;61:968.

5. Edson RS, Beckman TJ, West CP, Aronowitz PB, Badgett RG, Feldstein DA, et al. a multi-institutional survey of internal medicine residents'learning habits. Med teach. 2010;32:773-75.

6. Lai CJ, Aagaard L, Brandenburg S, Nadkarni M, Wei HG, Baron R. Multiprogram Evaluation of Reading Habits of Primary Care Internal Medicine Residents on Ambulatory Rotations. J Gen Intern Med. 2006 May; 21(5):486-86.

7. Fafard J, Snell L. Reading Habits of House Staff: what, where and why. Med teach.1989;11:279-83.

8. Leff B, Harper MG. The Reading Habits of Medicine Clerks at One Medical School: Frequency, Usefulness and Difficulties. Academic Medicine. 2006 May;81:5.489-94.

9. Choudhury N, Fletcher R, Soumerai S. Systematic review: the relationship between clinical experience and quality of health care. Ann Intern Med.2005;142:260-73.

10. Evans CE, Haynes RB, Gilbert JR, Taylor DW, Sackett DL, Johnson M. Educational package on hypertension for primary care physicians. Can Med Assoc J.1984;130:719-22.

11. Covel DG, Uman GC, Manning PR. Information needs in office practice: are they being met? Ann Intern Med.1985;103:596-99.

12. Norcini JJ, Lipner RS, Benson JA. An analysis of knowledge base of practicing internists as measured by the 1980 recertification examination. Ann Intern Med.1985;102:385-89.

13. Ramsey PG, Carline DJ, Inui TS. Changes over time in the knowledge base of practicing internists. JAMA.1991;266:1103-7.

14. Seelig CB. Changes over time in the knowledge acquisition practices of internists. South Med J.1993 Jul; 86(7):780-83.

15. Johnson KH, Dayrit M, Bazargan M. The reading habits of family practice residents. Fam Med.1997;29:488-91.

16. Barnard A, Kamien M. The reading habits of RACGP training program doctors. AustFam Physician.1994;23:1752-60.

17. Piterman L.GRs as learners. Med J Aust.1991;155: 318-22. 